\title{
Self-parody and Self-reflexivity in Norman Frederick Simpsonl's A Resounding Tinkle
}

\author{
Anindita Das, Dr. Dipendu Das \\ (Assistant Professor, Department of English, N. N. Saikia College, Titabar, India), \\ (Associate Professor, Department of English, Assam University, Silchar, India)
}

\begin{abstract}
Parody is a work that mocks an original work by means of ironic imitation. Parody has been regarded as the most representative artistic device and as the catalysing agent of artistic experimentation, creation and innovation in the $20^{\text {th }}$ century. A subset of parody is self-parody in which artists parody their own work. Simpson's play A Resounding Tinkle (1957) is a glaring instance of self-parody. His dramatic technique is phenomenally self-reflexive and self-consciously experimental; it involves parody, mockery, wit and humour. Simpson suggests that all language or behaviour is a manifestation of the ludicrous and the absurd. Absurdism implies the philosophy of insanity of the human condition, in a world devoid of meaning and significance, and detached from the pathetic and futile attempts man makes to render himself meaningful. It states that this vacuum or void is reality and that this reality must be recognized in all its nothingness and senselessness. The recognition of such a fact results in a sense of existential disillusionment which alienates man both from the world outside and from his own self. However, this sense of alienation is not the cause of anguish in Simpson. It is rather the cause of laughter, self-mockery, self-parody and even celebration. This paper is an attempt to study the representation of human condition in Simpson's play A Resounding Tinkle in the light of the dramatic devices of self-parody and self-reflexivity.
\end{abstract}

Keywords: Self-parody, Absurdism, disillusionment, alienation, self-mockery, self-reflexivity.

\section{Introduction}

Parody is an imitative work created to mock or trivialise an original work - its subject matter, author or style - by means of ironic or satiric imitation. Numerous instances of parody are found in literature. According to some critics, parody seems to lie somewhere between pastiche (i.e., a composition in another artist's manner, without satirical intent) and burlesque (which deals with the material of high literature and adapts it to low ends). In the 20th century, parody has been heightened as the central and most representative artistic device, as the catalysing agent of artistic experimentation, creation and innovation. This most prominently happened in the second half of the century with Postmodernism. However, earlier Modernism and Russian Formalism had anticipated this perspective. A subset of parody is self-parody in which artists parody their own work. Simpson's play A Resounding Tinkle (1957) is a glaring instance of self-parody. His characteristic dramatic style may be looked upon as that of a farce in a new dimension. Farce as a dramatic genre is associated with hackneyed and stereotyped flat characters, intricate improbable situations and an all-pervasive sense of the ridiculous. Farce is usually a sort of parody. Laughter is its most important ingredient. The dividing line between comedy and farce has never been specifically clear. In N. F. Simpson the plot is the stage action, the characters are generally one-dimensional, and the milieu is a fantasy world with parallels to our own. The fantasy is based on reality. Simpson's characters seem to be ordinary people caught in extraordinary situations. And, the comic effect springs from this incongruity. Simpson's humour derives from the fact that his characters are phenomenally deranged, which is to say, deranged according to a certain system: they apply inscrutable, anarchic and twisted logic to fantastic situations and they are trapped in patterns in both behaviour and language. A Resounding Tinkle is also remarkable for its self-reflexivity. The play consists of overt comments on its own making and creation. These explicit remarks have been made by the Author and Technician, who appear as characters in the play.

\section{A Resounding Tinkle-The Play}

A Resounding Tinkle (1957) opens with the couple Bro and Middie Paradock sitting at home and drinking wine in their suburban household when the door bell rings. Middie answers it and informs Bro that there is somebody at the door wanting Bro to form a government. The ensuing exchange about whether to form a government is followed by the arrival of the comedians who instantly act as a doctor-patient duo to entertain the couple. When they are left to themselves they erupt into a cascade of theories, scientific and otherwise, which seem a bit funny, absurd and monotonous at times. The audience is frequently reminded that they are watching a play. The Author appears on stage commenting on his own work and the comedians discuss the issue 
of audience-response and how to deal with it. A Technician takes over at one point to present a study on audience spontaneity. Finally, Bro's and Middie's elephant arrives but it is too big for their bungalow. When the play is almost over a circle of critics assembles on stage to discuss what they have witnessed so far. They wonder whether it is a farce or a parody of a farce; whether it is a comedy or tragedy. A Resounding Tinkle involves the patterns of verbal logic. At one point in the play the character Bro Paradock volunteers to be an electronic computer! Simpson mocks the mechanized life of postmodern man who behaves like an automaton. $A$ Resounding Tinkle is marked by paradoxes, puns and the literal handling of metaphors. Sometimes Simpson's use of humour in the play involves simple substitute of the logical expectation, such as when Uncle Fred changes not only his appearance but also his sex! What we find in the play is the ingenious misapplication of verbal logic that results in sheer ridiculousness. According to C. Z. Fothergill, "in his playing with the logical loopholes of language, Simpson has much in common with the nonsense of Lewis Carroll and of BBC Radio's Goon Show - a lunatic series of half-hour programmes enormously popular in the 1950s" [1]. In fact, Simpson's creatures would be perfectly at home in Carroll's wonderland as they all speak the same language. The nonsense of Simpson's make-believe world of fantasy and absurdity both mirrors and inverts our own world of matter-of-fact reality. Simpson's wonderland is inhabited and ruled by characters that seem to be systematically deranged and incapable of making sense to one another in terms of language. Simpson's pervading technique when presenting a situation is to displace the content but keep the form. Because they stick to the form with manic obstinacy his characters appear undoubtedly pleasant. Fothergill says that his characters are unaware of the substitution trick employed by Simpson, and, perhaps, we too are equally unaware that the same is true in our own lives. Thus, one might reasonably speak of a Christmas tree or a piece of furniture the way Bro and Middie Paradock discuss the elephant in A Resounding Tinkle. It is normal to want to look like a film actor or fashion model. However, it is absurd to want to look like an ape! It is reasonable to like wearing black. It is not reasonable to insist on a logical pretext for wearing black permanently, as Kirby insists in Simpson's One Way Pendulum (1959). In Fothergill's view, our lives, too, contain a good many forms from which the content has disappeared - the public, rituals and ceremonies, the compulsions of petty, meaningless social routines and so on. In that respect we too are ridiculous and eccentric. Reasonable and normal patterns of thought and action, as Simpson points out, are simply those quite arbitrary conventions which are generally accepted by people for no spectacular reason whatsoever. In order to demonstrate this fact Simpson takes a speech or behaviour pattern, scrambles the content and leaves the formal structure intact. For Simpson's characters, that seem to be puppet creatures, the form persists quite separate from the content which would render it meaningful. Very often it is found that the structure has a momentum of its own which entraps the characters, as when Bro Paradock in A Resounding Tinkle simply suggests Hodge for a name of the elephant and that triggers the comic naming routine. Thus, Simpson suggests that all language and behaviour contains the seeds of the ludicrous and the absurd.

\section{The Absurdist Technique in a Resounding Tinkle}

It seems to the reader or audience that Simpson's satire is implied and incidental. In contrast to former traditional comedy we are not laughing at misfits and outcasts while celebrating the social ideal. Nor are we witnessing the manic world of Ionesco's comedies, or the repressed and menaced world of Pinter's. Here in Simpson the entire stage, a world of its own, is laughable. It is the very tone which in the first place denies that Simpson's play A Resounding Tinkle is a serious, sustained satire. The characteristic tone is more funny and whimsical than sarcastic. The playwright aims to amuse, to mock, to delight, to shock, and not to attack and criticize. As the audience laugh their way out of the theatre they might recall some serious innuendo, or they might not. There may be a message or comment underlying the jokes, or there may not. Simpson's plays are not the subtly provocative application of critical intelligence, knowledge and scholarship. Secondly, moral standards, moral distinctions and moral issues are in no way consciously involved. What Simpson ends up suggesting is that humans are by nature silly and ridiculous, and that their words and actions are, therefore, meaningless, ludicrous and absurd. As a playwright, Simpson employs a number of techniques of the theatre of the absurd. The attack on mechanical lives and complacent routines, the concentration on both linguistic sterility and linguistic games, and the theatricalism, which reminds the audience that everything is fake, are absurdist traits Simpson is acquainted with. One might say that Simpson is doing consciously what he presents his characters doing unconsciously - speaking and behaving in persistent travesty of the conventionally accepted structures of explanation and value. Simpson employs the absurdist technique of deliberately flouting and debunking established standards and organizing principles. Thus, his characters are unaware of causal relationships. They invent justifications and pretexts, they assign causes to effects, but their explanations could apply equally well to any event. Simpson does not attack social conventions themselves; rather he mocks the inanities that occur within the conventional framework. This is true whether the referrent is religion, government, law, social institutions or domestic routines. Simpson is not questioning the existence of the values; he is demonstrating their limits. Nor does Simpson question the existence of meaning behind the definition of 
words. It is not that human comprehension is confronted by nothingness, but that the way things are is incomprehensible. The world, on every level, is nonsensical and devoid of meaning - but that does not mean the same as saying that it is, therefore, absurd. Absurdism implies the philosophy of insanity of the human condition, in a world having no meaning and significance, and detached from the pathetic and futile attempts man makes to render himself meaningful. It states that this vacuum or void is reality, and that this reality must be recognized in all its nothingness and senselessness. The recognition of such a fact results in a sense of existential disillusionment which alienates man both from the world outside and from his own self. However, this sense of alienation is not the cause of anguish in Simpson. It is rather the cause of laughter, self-mockery, self-parody and even celebration. Simpson gives us the laughter; he exposes the ridiculousness of human life. He also gives us a sense that this is a reality which must be confronted, celebrated and transcended. His plays do have a philosophical intent and understated message within the series of jokes. Simpson's plays embody existential concepts and principles. There is a consciousness of their plight on the part of the characters; they are gripped by a sense of isolation or futility, and to a great extent, the repressed hysteria on the verge of exploding or resulting in an outburst of laughter. There is at times a sense of parody and mockery beneath the laughter and jollity. The irrational and wild longing for meaning and clarity which is inevitably frustrated, and the anguish of the human predicament seem to find a very subtle and covert manifestation in Simpson. Some of his characters like Kirby in One Way Pendulum, Whinby in The Form (1961) and Bro Paradock in A Resounding Tinkle may be looked upon as absurdist anti-heroes. There is an implicit recognition by Simpson that the absurdist inanity matters in a significant way. However, he is not satirizing a vacuous reality to promote a positive alternative. Simpson is indulging his own lunatic vision in which everything seen from his perspective is sublimely and eternally inane. Though he ridicules life for relatively superficial reasons Simpson is definitely an Absurdist in the metaphysical sense. His plays are mostly a bundle of routines which can be easily relocated or omitted because there is hardly any organizing plot or unifying philosophy behind them. If it is a farce in a new dimension, it is only so in that his is a totally lunatic vision wherein everything is equally ridiculous and equally reducible to uncontrollable laughter.

\section{The Simpsonian Non Sequitur}

Simpson's work is uniquely all of a piece, all written in pretty well the same style, and all based on one fundamental principle, the non sequitur. This seems to link it with the Theatre of the Absurd, especially if we take into account the pronouncement of the author-character in A Resounding Tinkle that 'The retreat from reason means precious little to anyone who has never caught up with reason in the first place; it takes a trained mind to relish a non sequitur' [A Resounding Tinkle, 34] [2]. Simpson's plays seem to be parochial; they are in reality not merely so.

His plays are both universal and parochial at the same time. They are universal in the sense that they deal with the perennial issue of man's meaningless existence in a world that is indifferent and unintelligible to him. And, the parochialism of his plays, which largely has to do with the representation of the English suburban life, is aimed at arousing laughter and amusement in the English audience. Simpson's plays, especially $A$ Resounding Tinkle, parodies, mocks and satirizes English suburban life. As far as his style is concerned, Simpson has a tendency to demonstrate rather than just state something; to explore and examine every possibility of a joke and explain it by over-explicitness and rigid application of his twisted logic instead of merely sharing it. It seems that the laugh is not intended to be the final product of his dialogues and sallies, since when it comes at all it usually comes in the middle of an utterance, and not at the bitter end. Perhaps, he does this deliberately and intends us to see beyond the jokes to a deeper truth embodied in them - that the world is not logical and logic can be turned against itself to prove anything, since it all depends in human terms on a number of premises not open to question. What is remarkable about Simpson is his complete abandonment of any form of continuity. There is no plot in any normal sense of the term. Nor there is any attempt at character differentiation in Simpson's plays, for most of the lines may be equally well delivered by any character on the scene. The pattern of recurrent non sequiturs is strictly adhered to in every play by Simpson, so that the participants are not only nonexistent as individual characters but also unable to communicate with each other even at the most elementary level.

\section{Self-Parody and Self-Reflexivity In Simpson}

In John Russell Taylor's view, the first version of A Resounding Tinkle is of particular importance because in it we find Simpson the artist at his best and in a more elaborate way than elsewhere. As Taylor says, "Not only is there a character representing the author brought on to comment every so often, but there are a number of other direct acknowledgements from the stage that this is a play being performed, that the audience may have certain expectations and requirements, and that these are not being met. The picture of home life ...(all that is left in the final version) is here interrupted by the arrival of two comedians who perform a sketch in the kitchen and are then left by themselves to entertain the audience" [3]. What is most interesting about the play 
is that it is highly self-reflexive. In Act I, Scene Two of A Resounding Tinkle, the playwright seems to intervene as a character called the Author and comments on the play itself. He comments overtly on the play-its conception and representation. It is a glaring instance of self-reflexivity and even self-parody and self-mockery. He invites the audience to regards themselves as actors, and he declares that the actors are also spectators in their own right. The Author says to the audience in the very beginning of Act One, Scene Two:

"I agree. A pretty epileptic start. We're going to see what we can do in the next scene about pulling the thing together. Because this isn't at all of course how I wrote the play....There is no desire, no intention on my part, or on the part of any of us on this side of the footlights, to impose upon you any ready-made idea of our own as to what this play ought to turn out to be" [A Resounding Tinkle, Act I, Scene 2, 34].

The Author asks the audience to help him in his endeavour to shape the play. He tells the audience that he is one among them and that he too is eager to know what form and shape the play is about to take in the course of the representation. The persona called Author interrupts the audience in the middle of the play to reveal a few undisclosed facts to them:

"It is together that we must shape the experience which is the play we shall all of

us have shared" [A Resounding Tinkle, Act I, Scene 2, 34].

What makes this play unique is undoubtedly its overt self-consciousness that is marked by the way in which the persona called Author assigns a new and challenging role to the spectators or audience. He invites the spectators not just to interpret the play but also to shape it by participating in the making of the play:

"The actors are as much the audience as the audience themselves, in precisely the same way that the audience are as much the actors as the actors themselves. We are all spectators of one another, mutual witnesses of each other's discomfiture" [A Resounding Tinkle, Act I, Scene 2, 34].

It is this unusual self-reflexivity or self-consciousness that makes the play a unique instance of self-parody.

\section{Conclusion}

The dramatic technique employed in A Resounding Tinkle is phenomenally self-reflexive and selfconsciously experimental; it also involves parody, mockery, wit and humour. The playwright deals with serious issues about theatre in the manner of rendering a joke. He artfully blends the significant and the trivial, the serious and the comic by using the devices of paradox, understatement, hyperbole and anti-climax. The play is a typical self-parody. Besides being a parody of all lofty human aspirations, it is also unquestionably a parody of the creative aspirations of the playwright himself. Filled with witty word play, nonsensical remarks and plenty of satire at the expense of the middle classes, A Resounding Tinkle creates a world of ridiculousness that is mentally exhausting but unusually comic. It is N. F. Simpson's prime example of absurdist comedy that eschews plot in favour of a plunge into the inexplicable. According to Neema Parvini, when Simpson's plays are considered alongside other plays of the time - for example, John Osborne's Look Back in Anger (1956) - they appear far less dated by particular social contexts. However, the suburban settings of $A$ Resounding Tinkle seem to represent English suburbia of the 1950s. Simpson belongs to a class unto himself because his plays are without parallel on the English stage. His writing is entirely without wrath. Hilarious, benign, understated, whimsical, inconsequential and witty, it pays little attention to plot, characterisation or ideas, but preserves a consistent topsy-turvy sense of humour which owes almost nothing to the sort of social or political indignation motivating many of his peers. He is simply obsessed with a focus on the surreal in that his characters act like automata. They treat objects as sympathetically as one treats human beings. They allow every situation, however absurd, to develop to its logical conclusion which is arrived at by means of Simpson's characteristic application of twisted and anarchic logic. Simpson has all on occasions drawn on a range of Surrealist techniques to express man's predicament in an incomprehensible and irrational universe. A Resounding Tinkle does not discuss such human condition but represents it in absurd stage metaphors.

The Theatre of the Absurd was the major theatrical phenomenon of the 1950s, and it may be said that Simpson's absurd drama was played out against the backdrop of the Second World War. The basis of any wellmade, conventional play is the implicit assumption that the world does make sense, that reality is concrete and secure, and that this conception of reality is supported by certain moral standards, ethical codes and logical thought-processes handed down by tradition. The plays that belong to the Theatre of the Absurd, such as $A$ Resounding Tinkle, on the other hand, express a sense of shock at the absence or loss of any such clear and well- 
defined systems of beliefs or values. Such a sense of disillusionment, such a collapse of all formerly held firm beliefs is a characteristic feature of the Postmodern era. The social and spiritual reasons for such a sense of loss of meaning are varied and complex. Some of the reasons include the waning of religious faith that had started with the Enlightenment and led Nietzsche to speak of the death of God by the 1880s; the breakdown of the liberal faith in inevitable social progress in the wake of the First World War; the disillusionment with the hopes of radical social revolution as predicted by Marx after Stalin had turned the Soviet Union into a totalitarian regime; the relapse into barbarism, mass murder, and genocide in the course of Hitler's brief rule over Europe during the Second World War; and, in the aftermath of that war, the spread of spiritual hollowness in the otherwise outwardly prosperous and affluent societies of Western Europe and the United States. For many sensitive human beings the world of the mid-twentieth century had lost its meaning and had simply ceased to make sense. Previously held beliefs and certainties dissolved, the strongest foundations for hope and optimism collapsed. Suddenly man finds himself confronting a universe that is illogical, unfamiliar and even frightening in a word, absurd. All assurances of hope, all explanations of meaning have suddenly been unmasked as nonsensical illusions, empty chatter and meaningless preoccupations. Conversation among people seems to be reduced to an obscure babble of voices in an unknown language. Such a sense of an acute loss of the means of communication compels one to view the world, with the eyes of a total stranger, as a succession of frightening images. This sense of loss of meaning must inevitably lead to a questioning of the validity of human language as a recognised instrument for the communication of meaning. Hence, absurd drama is to a great extent concerned with a critique of language which has become devoid of meaning. The characters in Simpson's A Resounding Tinkle merely use language to fill the emptiness between them, to conceal the fact that they had no desire to tell each other anything at all. In other words, from being a meaningful instrument of communication language has become a kind of ballast filling empty spaces. Moreover, in a universe that seems to be drained of meaning, the pompous and tedious attempts at explanation of reality, which we call philosophy or politics, must appear as empty chatter. In A Resounding Tinkle Simpson parodies and mocks the nonsensical exchange between the suburban couple regarding the formation of a government. It cannot be denied that the bulk of everyday conversation is largely devoid of logic and sense, and is in fact nonsensical. It is at this point that the Theatre of the Absurd actually coincides with the highest degree of realism. For if the real conversation of human beings is in fact absurd and meaningless, the absurdist play may well be considered a meaningful representation of the reality of human condition in the world, in the postmodern world, to be more accurate. Simpson lays emphasis on the basic absurdity of the human condition, and also on the invalidity of all closed systems of thought with fake claims to provide a total explanation of reality. What is unique about Simpson is his focus, not merely on the failure of man to overcome the absurdity of human existence, but also on man's strange ability to celebrate the absurdity of his own affairs with a sense of self-parody while being self-conscious about his inescapable surrender to the incomprehensible forces of the world he inhabits.

\section{References}

[1] C. Z. Fothergill, "Echoes of 'A Resounding Tinkle': N. F. Simpson Reconsidered,” Modern Drama, XVI, 1973, 299-306.

[2] N. F. Simpson, A Resounding Tinkle (London: Faber and Faber, 2007).

[3] John Russell Taylor, "Presented at Court: N. F. Simpson," Anger and After: A Guide to the New British Drama (London: Methuen \& Co. Ltd., 1962). 